\title{
DA UNIVERSIDADE À ESCOLA: GESTÃO E ATITUDES LINGUÍSTICAS EM ATIVIDADES DE MEDIAÇÃO DE LEITURA NO PARAGUAI
}

DOI: $10.48075 / R I . V 2212.25349$

Franciele Maria Martiny ${ }^{1}$ Jocenilson Ribeiro ${ }^{2}$ Mariana Cortez ${ }^{3}$

RESUMO: Neste artigo pretende-se refletir sobre as atitudes linguísticas de discentes universitárias extensionistas no encontro com crianças de uma escola pública em Ciudad del Este, Paraguai, durante a realização de um projeto sobre mediação de leitura literária. Tendo como base as interpretações sobre as posturas e os comportamentos linguísticos (MORENO FERNÁNDEZ, 1998; GROSJEAN, 2011; CALVET, 2002) da equipe extensionista em contexto plurilíngue, como gestoras das línguas, por meio de seus relatos escritos sobre as atividades realizadas com as crianças, a análise dos dados trará direcionamentos sobre as políticas linguísticas oficiais e as praticadas (SPOLSKY, 2005, 2016; RAJAGOPALAN, 2011, 2013) pela Universidade e na escola do Paraguai focalizada. Depreendem-se dessa investigação alguns aspectos significativos, entre eles: 1) a diferença entre os relatos das mediadoras em sua relação com as línguas presentes no ambiente de mediação, evocando necessidades distintas para a interação; 2) o estranhamento inicial das universitárias em relação à fala em guarani/jopará dos alunos paraguaios; 3 ) a presença do português na fala das crianças e 4) o desenvolvimento e a necessidade de uma postura intercultural por parte das mediadoras a fim de favorecer o vínculo com as crianças, as quais também se posicionam de maneira a possibilitar o encontro com o "outro" apesar dos diferentes conhecimentos linguísticos.

Palavras-chave: Extensão Universitária; Gestão e Atitudes Linguísticas; Escola na Fonteira.

\section{FROM UNIVERSITY TO SCHOOL: MANAGEMENT AND LANGUAGE ATTITUDES IN READING MEDIATION ACTIVITIES IN PARAGUAY}

ABSTRACT: This paper intends to reflect on the linguistic attitudes of university extension students in the encounter with children from a public school in Ciudad del Este, Paraguay, through a literary reading mediation project. Based on interpretations about linguistic attitudes and behaviors (MORENO FERNÁNDEZ, 1998; GROSJEAN, 2011; CALVET, 2002) of the extension team in a multilingual context, as language managers, through their written reports on the activities performed with the children, data analysis will bring directions on official and actual language policies (SPOLSKY, 2005, 2016; RAJAGOPALAN, 2011, 2013) at the University and a school in Paraguay. Some significant aspects are instilled from this study: 1) the difference between the mediators' reports in their relationship with the languages present in the measurement environment, evoking distinct needs for interaction; 2) the initial strangeness of the university students in relation to the Guarani/Jopará

\footnotetext{
${ }^{1}$ Franciele Maria Martiny, doutora em Letras, professora adjunta da área de Letras/Linguística na Universidade Federal da Integração Latino-Americana - Foz do Iguaçu-PR: franmartiny@hotmail.com

2 Jocenilson Ribeiro, doutor em Linguística, professor adjunto na Universidade Federal de Sergipe - São Cristóvão-SE, email:jonuefs@gmail.com

3 Mariana Cortez, doutora em Letras, professora da área Letras/Linguística na Universidade Federal da Integração Latino-americana - Foz do Iguaçu-PR: macortez74@hotmail.com
} 
language of Paraguayan students; 3) the presence of Portuguese in the spoke of children; and 4) the development and need for an intercultural posture on the part of mediators in order to favor the bond with children, who are also positioned in a way to enable the encounter with the "other", despite their different linguistic knowledge.

Keywords: University Extension; Management and Linguistic Attitudes; School at the Frontier.

\section{INTRODUÇÃO}

Estabelecer o diálogo entre a universidade e a comunidade exige gestos, tempos e cuidados mútuos porque enlaça dois "campos institucionais" e, consequentemente, discursivos, regidos por diferentes ordens, enredados em normas, jogos de regras, funcionamento político, constituindo os dispositivos que controlam nossas práticas, revelam atitudes e se materializam em discursos. Sobrepostas a esse entrecruzar, as experiências realizadas com as comunidades na Tríplice Fronteira (Argentina, Brasil e Paraguai) geralmente impõem um complexo desafio: o linguístico.

No caso específico das intervenções realizadas pela universidade focalizada neste estudo, acentua-se a situação/tensão linguística já que o grupo de docentes e discentes universitários é linguística e culturalmente bastante diverso da comunidade escolar na qual atuam. Como estabelecido em seu Plano de Desenvolvimento Institucional-PDI (BRASIL, 2013), tal instituição de ensino superior tem como princípios filosóficos e metodológicos institucionais a interdisciplinaridade, a interculturalidade, o bilinguismo e o multilinguismo, a integração solidária e a gestão democrática. No último PDI (BRASIL, 2019), foram acrescidos mais três princípios, i. e., a ética, os direitos humanos e a equidade étnico-racial e de gênero e a sustentabilidade e bem-estar. Assim sendo, suas atividades fins de ensino, pesquisa e extensão visam a propiciar experiências que possibilitem essa formação.

Estas atividades devem estar articuladas de tal maneira que a universidade promova aos egressos uma formação humana e científica com base nestes princípios, como é possível observar no modo como ela concebe o perfil do egresso:

Os egressos [...] deverão obter sólida formação humana e técnico-científica, devendo ser capazes de refletir criticamente e selecionar informações importantes em suas áreas de trabalho, cultura e exercício da cidadania. Comprometidos com princípios éticos, deverão ser capazes de avaliar, propor e atuar desenvolvendo soluções adaptadas às peculiaridades da América Latina e Caribe. Neste contexto, terão a possibilidade de aprender 
constantemente, buscando espaços intermediários, solidários e integradores entre os conteúdos acadêmicos e a aplicação de conhecimentos multidisciplinares. Além disso, possuirão uma postura transformadora e humanística, cuja base solidificará a capacidade de analisar os problemas latino-americanos e caribenhos sob as perspectivas das diversas culturas envolvidas. (BRASIL, 2013, p.18)

Com o intuito de promover ambientes propícios à concretização dos princípios universitários, os estudantes e os docentes participantes deste contexto atuam em projetos de extensão, sendo, muitas vezes, "externos" à comunidade. Por isso, é objetivo da universidade buscar "romper" com seus muros para refletir com e sobre as demandas de um determinado grupo, região, bairro, cidade etc. Na Tríplice Fronteira, local em que a instituição de ensino superior está localizada, além do encontro com realidades sociais e territoriais diferentes, há, sobretudo, o encontro com muitas línguas, já que o grupo que transita entre o espaço universitário e a escola é conformado por sujeitos advindos de contextos diversos, com modos de falar bastante característicos e diferenciados em cada país ou região.

Assim, este artigo pretende refletir sobre as atitudes linguísticas das discentes universitárias no encontro com as atitudes das crianças de uma escola pública em Ciudad del Este, Paraguai, por meio da realização do projeto de pesquisa, extensão e ensino "Vivendo Livros Latinos-Americanos na Tríplice Fronteira" ${ }^{4}$. Em termos de contribuição, a análise dos dados poderá oferecer direcionamentos sobre as políticas linguísticas oficiais e as praticadas pela Universidade e na escola paraguaia, partindo das interpretações sobre as posturas e os comportamentos linguísticos da equipe extensionista em um contexto plurilíngue como gestoras das línguas, bem como dos discentes participantes das atividades, que estão presentes nos relatados das extensionistas.

Para tanto, esta reflexão está dividida em três seções: 1) diretrizes da Universidade recorre-se a uma breve análise discursiva dos documentos orientadores da instituição, procurando relacionar as ideias de integração, interdisciplinaridade e plurilinguismo às propostas de ensino, pesquisa e extensão, articulando aspectos teóricos de políticas e

\footnotetext{
${ }^{4}$ A ação é realizada pela Unila, desde 2014, sendo que seus principais objetivos são: a) recuperar os espaços de leitura e b) desenvolver práticas de mediação de leitura literária em escolas da região de fronteira: Ciudad del Este (Paraguai), Foz do Iguaçu (Brasil) e Puerto Iguazú (Argentina). Além disso, o projeto de pesquisa é realizado com financiamento do CNPq/UNIVERSAL no 425119/2016-5 e EDITAL PRPPG/UNILA № 137, DE 8 DE NOVEMBRO DE 2018.
} 
Dossiê: Atitudes Linguísticas e Políticas Linguísticas: abordagens interdisciplinares

atitudes linguísticas, bem como ao contexto sociolinguístico paraguaio; 2) aspectos metodológicos da pesquisa com a descrição do projeto e de suas atividades e 3) análise interpretativa de sequências de enunciados dos diários de campo (BORTONI-RICARDO, 2008), no qual são retomados os registros etnográficos (GEERTZ, 2008 [1926]) produzidos pela equipe extensionista a fim de verificar as posturas e os comportamentos linguísticos das ${ }^{5}$ discentes envolvidas na mediação.

\section{POLÍTICAS E ATITUDES LINGUÍSTICAS EM CONTEXTOS PLURILÍNGUES}

Para compreender um pouco mais o perfil deste discente universitário em formação, é importante caracterizar o espaço que o acolhe, a Universidade. Trata-se de uma instituição de ensino superior pública, criada a partir de uma política de democratização do acesso à educação superior no Brasil, pela Lei no 12.189, de 12 de janeiro de 2010. Por sua abrangência e missão é composta por uma comunidade linguística heterogênea e sociolinguisticamente complexa haja vista, primeiramente, a própria localização geográfica situada na fronteira trinacional, Brasil-Argentina-Paraguai, e, para além disso, nesse ambiente em que convivem sujeitos de mais de 30 nacionalidades $^{6}$, que interagem a partir de diversos falares.

Apesar de apresentar esta superdiversidade (VERTOVEC, 2007; BLOMMAERT, 2013) ${ }^{7}$, - Estatuto da Universidade, aprovado em 2012, e o seu Plano de Desenvolvimento Institucional - PDI (2013 - 2017) ${ }^{8}$ voltam-se para uma política educacional bilíngue centrada no português-espanhol para o desenvolvimento latino-americano. Há que se considerar que, embora a universidade seja oficialmente bilíngue e reconhecidamente plurilíngue, não há uma política linguística oficial claramente estabelecida (CARVALHO, 2012; FERREIRA, 2015;

\footnotetext{
${ }^{5}$ Optou-se por usar sempre o feminino em referência às extensionistas universitárias, pois são mulheres.

${ }^{6}$ A Universidade possui alunos, docentes e técnicos administrativos oriundos de vários estados do Brasil e de demais países da América-Latina, do Caribe e, ainda, a partir de 2019, a instituição recebeu discentes refugiados e portadores de visto humanitário de 32 nacionalidades, procedentes da Europa, África e Ásia, além de estudantes oriundos de povos indígenas aldeados da América do Sul. Disponível em: https://portal.unila.edu.br/noticias/processos-de-selecao-internacional-recebem-1-709-inscricoes-de-26paises/seleorefugiadosevistohumanitrio.png/view>. Acesso em: 20 jun. 2020.

7 Termo utilizado pelo autor para designar a diversificação da diversidade.

8 Embora o PDI esteja em vigência para o quinquênio 2019-2023 (BRASIL, 2019), baseia-se no PDI anterior (2013 - 2017), tendo em vista que as ações do projeto estavam amparadas cronologicamente naquele quinquênio.
} 
Dossiê: Atitudes Linguísticas e Políticas Linguísticas: abordagens interdisciplinares

CARVALHAL, 2016; MUÑOZ, 2016; RIBEIRO, NUNES, 2020) no intuito de se promover o espanhol e o português nos vários âmbitos de uso, ensino, textualização, documentação organizacional e gestão das línguas de mesmo modo igual nos espaços de enunciação. Tal cenário evidencia a complexidade de um espaço intercultural, pluriétnico e multilíngue no que diz respeito às disputas, aos atravessamentos de relações de poder entre seus participantes, falantes, e ao papel dos gestores que podem ainda ter posturas baseadas em uma visão restrita e colonialista sobre o papel que as línguas podem assumir nesses contextos plurilíngues.

$\mathrm{Na}$ perspectiva deste trabalho e do modo como os autores concebem a política linguística no contexto de atuação do projeto, ultrapassa-se a fronteira institucional e oficial dessa concepção de política, pois se consideram dois fatores fundamentais como autogestão do funcionamento das línguas. O primeiro diz respeito ao próprio contexto da Universidade em que os diversos falantes e as muitas línguas interagem, estão em contato, apresentam um modo de existir e resistir de suas línguas independentemente de que haja uma intervenção oficial de grupos e/ou instituições. Sobre esse caso em particular, há o exemplo das línguas francesa e crioula (kreyòl ayisyen) recorrentes nos espaços da Universidade ou da cidade por onde circulam os haitianos. O segundo fator refere-se ao próprio contexto escolar de atuação do projeto em que as línguas guarani/jopará, espanhol e português assumem um papel político no mesmo espaço de enunciação ${ }^{9}$, o que não significa evidentemente que todas elas tenham o mesmo papel sociolinguístico e sociopolítico na escola e em seu entorno. Esse aspecto será demonstrado na seção analítica deste artigo.

Da mesma forma que a língua influencia comportamentos, os comportamentos influem sobre as línguas, por isso não podem ser dissociados (CALVET, 2007, p. 130). Nesse ínterim, os falantes da língua minoritária, em cenários plurilíngues, são geralmente o grupo mais afetado pelas atitudes de diferentes grupos sociais com relação à língua adotada. Segundo Grosjean (2001), as consequências das atitudes negativas, por exemplo, podem incluir desde a crença dos falantes de que não conhecem bem nenhuma das línguas de que são usuários até a completa substituição da língua minoritária pela majoritária.

\footnotetext{
${ }^{9}$ Baseia-se aqui na concepção de espaço de enunciação na linha de análise de Guimarães (2006) e Sturza (2010).
} 
Uma atitude linguística, portanto, consiste em uma postura ou comportamento positivo ou negativo ante a uma língua ou a uma variedade linguística particular, uma reação favorável ou desfavorável face ao modo de falar do outro (GROSJEAN, 2001), sendo compreendida, neste estudo, como gestos de política linguística. Destarte, as atitudes linguísticas são influenciadas por fatores contextuais e por constructos históricos e, embora sejam individuais, têm origem em um comportamento coletivo, construídas ao longo do processo de socialização e (re)produzidas no cotidiano, influenciando o comportamento linguístico (MORENO FERNÁNDEZ, 1998; CALVET, 2002). Considera-se, assim, que a atitude linguística é o resultado da soma de suas crenças, conhecimentos, afetos e tendências a comportar-se de forma determinada diante de uma língua ou de uma situação sociolinguística.

Por sua vez, as políticas linguísticas, de acordo com Maher (2013), são as intervenções nas línguas, tanto por parte dos falantes como por parte do Estado, levando em conta como essas são constituídas, percebidas e utilizadas. Entende-se, dessa forma, que as políticas linguísticas constituem as línguas, contemplando valores e funções a partir dos usos linguísticos que fazem seus falantes.

De acordo com os trabalhos de Spolsky $(2005,2016)$ e Rajagopalan $(2011,2013)$ é preciso assumir essa noção mais ampla do que seria política linguística, como uma visão multidimensional do conceito, não mais restrito a ações desencadeadas por governos e organismos institucionais autorizados, mas que envolvem, ao mesmo tempo, outros domínios, com a ação de outros agentes. Fortemente implicado nessa discussão está o espaço escolar, em que há outros atores significativos que podem ser responsáveis pelo planejamento e pela gestão das políticas educacionais e linguísticas, seja com atitudes impositivas seja com democráticas.

\section{CONTEXTO LINGUÍSTICO PARAGUAIO}

Diante desse contexto, para compreender as políticas em torno das línguas e sua gestão, é importante entender como se dão os (des)encontros linguísticos de um determinado local. No caso deste estudo, é relevante refletir sobre o lugar da língua guarani (e da variante jopará) em relação ao contexto plurilíngue das ações do projeto, observando a 
configuração linguística do Paraguai e no espaço de enunciação da Ciudad del Este (na fronteira). Há uma política educacional implantada a partir da reforma educativa que passou a promover uma educação bilíngue (BOYER, 2019), cenário político que acolhe essa ação de ensino, pesquisa e extensão.

Para tanto, será apresentado, neste momento, um pouco mais sobre o cenário plurilinguístico paraguaio. Sobre isso, verifica-se que o guarani goza do estatuto jurídico de língua cooficial a partir da Ley de lenguas (No. 4251) ${ }^{10}$, que criou a Secretaría de Políticas Lingüisticas (SPL) ${ }^{11}$ e a Academia de la Lengua Guarani ${ }^{12}$, entretanto, não goza dos mesmos status políticos e simbólicos de que desfruta o espanhol em todas suas funções sociais, como estabelece a referida lei no Artigo 2 ao tratar da pluriculturalidade.

De modo paradoxal, segundo Boyer (2019), o guarani é majoritariamente uma língua falada no país nas relações socioculturais cotidianas, todavia ainda sofre dos estigmas que, historicamente, o desprestigiaram e o minimizaram face às situações sociopolíticas, econômicas, científicas e culturais do espanhol, que também é cooficial. Esse paradoxo, envolvendo a relação e o status social da língua guarani como língua nacional, sem os mesmos prestígios do espanhol, tem sido objeto de estudo etnossociolinguístico de Henri Boyer, que analisa a configuração desse falar a partir da reforma educativa no Paraguai em 1994. Segundo o autor:

Como es sabido, el Paraguay donde se habla mayoritariamente el guaraní (paraguayo), lengua descendiente de la familia amerindia tupí-guaraní, que se ha podido considerar dominante y dominado (Melià 1997 [1988] — presenta una configuración etnosociolingüística (de tipo diglósico o más bien pluriglósico) particularmente interesante. Hoy en día, esta configuración está en plena evolución con la aplicación de una reforma educativa que tiene como objetivo promover la educación bilingüe en todo el país. A pesar de que todos los indicadores institucionales auguran ruptura con un largo período de minoración (en el que el guaraní estuvo alternativamente excluido de la escuela, estigmatizado con la designación de guarango y mitificado, objeto de fetichismo), uno se pregunta si la representación ambivalente hacia el idioma de los orígenes -símbolo casi unánime de la identidad nacional a pesar de ser despreciado y minorizado (Manrique Castañeda, apud Melià 1997 [1988]: 44) - pertenece ya al pasado. De hecho, diversas observaciones llevan a pensar que la actitud

\footnotetext{
10 PARAgUAY. Poder legislativo. Ley No. 4251 De Lenguas. Disponível em: <https://www.bacn.gov.py/archivos/2895/20141202094319.pdf>. Acesso em: 02 jun. 2020.

${ }^{11}$ Disponível em: <http://www.spl.gov.py/>. Acesso em: 02 jun. 2020.

${ }^{12}$ Disponível em: < http://academiadelalenguaguarani.org.py/>. Acesso em: 02 jun. 2020.
} 
paradójica sufrida por la lengua guaraní, como lengua dominada, no ha desaparecido realmente. (BOYER, 2019, p. 42-43, itálico do autor; negrito nosso) $)^{13}$.

Da análise de Boyer (2019), podem-se destacar duas questões que parecem essenciais para refletir sobre o papel e o lugar da língua na escola envolvida no projeto. A primeira diz respeito à diferença entre uma concepção de língua estândar (guarani promovida na escola no processo educativo e a presença de uma língua em uso/falada pelas crianças, professores, gestores escolas e pela comunidade no entorno da referida instituição de ensino, além da convivência com o espanhol (castellano). É nessa diferença que se instaura uma questão de nomeação da língua e suas representações, muitas vezes inconscientes para muitos de seus falantes, o que leva a pensar na coexistência de duas línguas: o guarani e o jopará (yopara). A segunda questão é da ordem dos discursos sobre a língua guarani, como analisa Zuccolillo (2000).

Existe uma memória compartilhada e generalizada na história latino-americana constituída na retórica positivista da ciência colonialista que atribuiu valores disfóricos e eufóricos, respectivamente, para línguas originárias e línguas do colonizador. É nesse sentido que Mariani (2004, p.19) define colonização linguística como “[...] um processo histórico de confronto entre línguas com memórias, histórias e políticas de sentidos dessemelhantes, em condições assimétricas de poder tais que a língua colonizadora tem condições políticas e jurídicas para se impor e se legitimar relativamente à(s) outra(s), colonizada(s)". Tal diferença se institucionaliza historicamente produzindo efeito de sentidos e valorização sobre as línguas como o que sublinhamos acima nas palavras de Henri Boyer, i. e., a atitude paradoxal de que sofre o guarani mesmo havendo instrumentos, políticas e ações para a valorização destas línguas minoritárias (Cf. ALTENHOFEN, 2013) em contexto de pluriglossia.

\footnotetext{
${ }^{13}$ Como se sabe, no Paraguai, fala-se majoritariamente o guarani (paraguaio), essa língua descende da família ameríndia tupí-guarani pode ser considerada dominante e dominada (MELIÀ, 1997 [1988] - pois apresenta uma configuração etnossociolinguística (diglóssica ou melhor, pluriglóssica), particularmente interessante. Hoje em dia, esta configuração está em plena evolução em razão da aplicação de uma reforma educacional que tem por objetivo promover a educação bilíngue em todo o país. Apesar de todos os indicadores institucionais vislumbrarem uma ruptura com um longo período de minoração (no qual o guarani esteve ora excluído da escola estigmatizado com a designação guarango, ora mitificado como objeto de fetichismo), nos perguntamos se a representação ambivalente em relação aos idiomas originários - símbolo quase unânime da identidade nacional, apesar de ser depreciado e minorizado (CASTAÑEDA, apud MELIÀ, 1997 [1988], p. 44) pertence já ao passado. De fato, diversas observações levam a pensar que a atitude paradoxal sofrida pela língua guarani, como língua dominada, não desapareceu realmente. (BOYER, 2019, p. 42-43, tradução das autoras)
} 
Mas é preciso considerar que, ao se tratar de relação entre línguas em espaço de enunciação plurilíngue, não se pode em nenhuma hipótese abandonar o aspecto do "valor" e da "valoração" posto em evidência no modo como seus falantes se relacionam com estas línguas e como o outro as enxergam. Há diferentes atitudes positivadas ou não quando se trata de usar e se apropriar dessa língua. Nesse sentido, embora Altenhofen (2013) trate de política linguística das línguas minoritárias no contexto brasileiro, diferentemente do contexto paraguaio, onde as relações entre espanhol-guarani-jopará funcionam de outra maneira, sua concepção de "língua minoritária" se adequa ao modo como se está pensando a língua guarani aqui, considerando o aspecto histórico e econômico implicado no valor simbólico e subjetivo da língua. Para o autor, que parte de "[...] diferentes vozes e perspectivas de análise do contexto brasileiro" (ALTENHOFEN, 2013, p. 93):

\footnotetext{
Basta ter em mente que toda e qualquer língua, seja ela minoritária ou majoritária, possui uma importância e um valor no "mercado linguístico" que dependem de uma série de fatores. É uma ilusão pensar que as línguas são iguais, no sentido do que são capazes, mas todas - sem exceção - têm o seu valor definido pelos usuários e respectivas comunidades de fala, a quem deve ser garantido o direito de uso. Esse valor de mercado, assim como o status sócio-político de uma língua, variam conforme o contexto de uso e o ponto de vista que se adota. (ALTENHOFEN, 2013, p. 95).
}

Zuccolillo (2000), por sua vez, analisou os discursos nacionalistas paraguaios que, no início do séc. XX, sustentaram as políticas linguísticas oficiais instituídas a partir das décadas 1940/1950, sendo reafirmados nos regimes totalitários, “[...] como é o caso da ditadura militar do General Alfredo Stroessner (1954-1989), período durante o qual tais discursos se reafirmaram de modo mais decisivo." (ZUCCOLILLO, 2000, p. 9) A linguista descreve seu objeto, discutindo a constituição do aspecto político e ideológico no interior do apagamento do caráter político dos discursos sobre a língua pela suposta naturalização que clássicos trabalhos "científicos" sobre o guarani e o próprio regime de Stroessner promoveram mediante a ideia de "nacional". Portanto, a língua guarani (supostamente real, pura e natural) e o jopará (concebido como resultante de uma aglutinação, uma "mistura" de espanhol com guarani) dispõem de representações ambíguas (elogiosas, naturalistas, nacionalistas, racistas e xenófobas) a partir das quais são vistas como 'expressão dos afetos', 
Dossiê: Atitudes Linguísticas e Políticas Linguísticas: abordagens interdisciplinares

da família, da ação, mas também de desprestígio dado o valor "primitivo" e "incivilizado" que thes foi historicamente atribuído.

Ao se fazer qualquer tentativa de descrição e/ou interpretação de um objeto de estudo na esfera dos estudos de linguagem ou de educação minimamente demarcado no Paraguai, inevitavelmente os pesquisadores, linguistas, são impelidos a pensar a partir de duas constatações que são da ordem da identidade nacional, como analisaram Zuccolillo (2000) e Rodriguez-Alcalá $(2001,2002)$. A primeira constatação diz respeito à identidade étnica que reclama a memória discursiva da pré-existência dos povos originários e do contato litigioso com o colonizador. Destaca-se o aspecto litigioso desse contato por considerar que tal processo histórico não se deu de forma harmônica, coexistindo um discurso de bilinguismo hegemônico. Sabe-se que o espanhol e o guarani, no contexto panamericano, não gozam do mesmo status glotopolítico (cf. ARNOUX, 2000; ARNOUX, VALLE, 2010). Já a segunda constatação é a de que a identidade etnossociolinguística (BOYER, 2019) funciona como resistência naquele país, vindo lograr, após travar lutas históricas, a aprovação e a promulgação da Ley de Lenguas em 2010. Isso implica diferentes relações de força e manutenção de poder no processo de distribuição das línguas (originárias e coloniais) de forma desigual, necessitando, portanto, de uma gestão glotopolítica e de políticas linguísticas que operem a partir de diferentes esferas (jurídica, política, científica, educacional). Nesse sentido, o trabalho político não se restringe a uma postura institucionalizada apenas ou oficializada através de um governo no sentido macro, mas das microações que valorizam ou não o plurilinguismo, como se observa na noção de política linguística ampliada em que outros agentes, além do Estado, possuem papel de gerir as intervenções nas línguas a partir de suas posturas (SPOLSKY, 2005; 2016).

A literatura linguística paraguaia que tem se voltado a temas como políticas linguísticas, legislação e direitos linguísticos, nacionalismo linguístico e a questão do bi/plurilinguismo paraguaio (ZUCCOLILLO, 2000; RODRIGUEZ-ALCALÁ, 2001, 2002; BOYER, 2007, 2016, 2019; NIRO, 2012; PENNER, 2010, 2016a, 2016b) é, pois, unânime ao reconhecer a complexidade da própria configuração linguística daquele país e da imbricação de identidades a partir de duas línguas oficiais, num contexto plurilíngue, de línguas constantemente em contato e, particularmente, na fronteira onde o português (e demais línguas de negócios em Ciudad del Este) coexistem. Assim, percebe-se que a situação 
Dossiê: Atitudes Linguísticas e Políticas Linguísticas: abordagens interdisciplinares

plurilíngue do Paraguai se impõe como problema de identidade e representação vinculado ao fator político-ideológico que promove as línguas de modo desigual. Mas também a existência de um discurso e de "[...] una percepción bilingüista en relación con un elogio nacionalista del mestizaje" (BOYER, 2019, p. 42) ${ }^{14}$.

Para compreender esta complexidade, situando as análises no interior de uma prática de mediação de leitura em Ciudad del Este, é preciso pensar que as ações do projeto focalizado, neste estudo, fazem parte de uma política pautada no conceito de plurilinguismo estudado e debatido no ambiente universitário. As extensionistas são expostas, portanto, a esse contexto superdiverso. Por meio dos relatos etnográficos (GEERTZ, 2008 [1926]), este artigo apresenta como elas se assumem mediadoras (gestoras) desses (des)encontros linguísticos, nos quais o jopará resiste predominantemente como língua oral nas interações e nas relações cotidianas das crianças e da comunidade escolar, transitando aí entre o guarani escolar, o espanhol como língua dominante e prestigiada e o português língua de fronteira (atravessada pelo espanhol como segunda língua) que brasileiros extensionistas usam nas práticas de mediação de leitura.

\section{ASPECTOS METODOLÓGICOS DA PESQUISA E DESCRIÇÃO DO ESPAÇO ESTUDADO}

A fim de colocar em discussão a situação descrita, optou-se por conduzir uma pesquisa que leva em consideração o contexto de interação entre a escola e a universidade. A proposta de mediação de leitura literária analisada tinha por objetivo aproximar as extensionistas de um grupo de aproximadamente 15 crianças de uma escola urbana periférica de Ciudad del Este, Paraguai. Os encontros foram registrados em forma de relato etnográfico, pois compreende-se que o pesquisador (aluno extensionista) é um agente ativo na investigação (BORTONI-RICARDO, 2008) e que, por isso, elabora, atua, questiona e analisa sua prática. É possível afirmar que a postura metodológica adotada para a redação dos relatos tem em vista a definição de etnografia defendida por Geertz (2008 [1926]). Para o autor: “[...] a etnografia é como tentar ler (no sentido de 'construir uma leitura de') um manuscrito estranho, desbotado, cheio de elipses, incoerências, emendas suspeitas e

\footnotetext{
14 “[...] uma percepção bilíngue em relação ao elogio nacionalista da mestiçagem” (BOYER, 2019, p.42, tradução das autoras)
} 
Dossiê: Atitudes Linguísticas e Políticas Linguísticas: abordagens interdisciplinares

comentários tendenciosos, escritos não com os sinais convencionais do som, mas como exemplos transitórios do comportamento modelado" (p. 7). Ao todo, as universitárias produziram 12 relatos de 6 encontros com as crianças do 50 Grado (10 a 12 anos) no período de 11 de setembro a 14 de novembro de 2019.

Reforça-se que, apesar de o projeto de extensão ter por objetivo geral revitalizar o espaço bibliotecário e propor práticas de mediação de leitura literária, o contexto linguístico possibilitou refletir acerca da formação de estudantes de uma universidade, que como apresentado anteriormente, pretende que seus egressos sejam profissionais atentos à diversidade cultural e social.

O plano de trabalho das mediações visava à apreciação literária e fruitiva de contos sobre selva e animais e, especialmente, o foco estava na leitura dos contos do autor argentino Horacio Quiroga (La guerra de los yacarés, Las medias de los flamencos e El loro pelado) editados no livro Cuentos de la selva. Ademais, desde o início da atuação do projeto de extensão na referida escola em 2018, identificou-se a necessidade de uma aproximação "intercultural", em que o encontro com o "outro" possibilita a reflexão sobre si (WALSH, 2012; CANDAU, 2012). Para tanto, a literatura, por sua potência humanizadora, favoreceu essa aproximação com a seguinte proposição: "nós alunas extensionistas lemos histórias para vocês (estudantes) e vocês nos ensinam guarani e juntos produzimos um conto bilíngue (espanhol e guarani)".

Para introduzir o tema "narrativas na natureza", foram utilizados os contos ilustrados: O túnel, de Anthony Browne, Eloísa y los bichos, de Jairo Buitrago e Rafael Yockteng e Salvaje, de Emily Hughes. Essas leituras coletivas propiciaram uma reflexão inicial sobre a natureza em sentido literal e metafórico, como também aparece nos contos de Horacio Quiroga, e estimulou-se a imaginação das crianças para transformar a biblioteca em uma "selva", convidando-as a adornar o espaço com elementos que remetessem ao lugar representado nos contos lidos.

Entende-se que este processo de evocação do real e da fantasia possibilita um encontro fluído e um ambiente favorável para a aproximação das mediadoras e nele é possível refletir sobre os (des)encontros linguísticos. Para acompanhar o desenvolvimento das práticas de mediação de leitura, a coordenadora da ação solicitou às extensionistas que registrassem a experiência a partir da seguinte orientação : "redijam em forma de relatos, 
Dossiê: Atitudes Linguísticas e Políticas Linguísticas: abordagens interdisciplinares

em 1ạ pessoa, o que chama a atenção de vocês durante o encontro, utilizem a linguagem coloquial e a estrutura de uma narrativa". Os recortes expostos na sequência são perspectivas individuais, avaliadas e autoavaliadas por toda a equipe do projeto. Mantém-se aqui a forma da grafia dos relatos conservando a expressão das extensionistas, inclusive no uso de distintas línguas.

Delineia-se, a seguir, um pouco mais do perfil das quatro universitárias extensionistas, todas mulheres, de faixa etária entre 18 a 28 anos, incluindo dados sobre formação acadêmica, nacionalidade, línguas que falam e a frequência com que participaram dos encontros:

\section{Quadro 01 - Perfil das discentes universitárias participantes do projeto}

\begin{tabular}{|c|c|c|c|c|}
\hline Mediadoras $^{1}$ & Formação acadêmica & Nacionalidade & Línguas faladas & Frequência \\
\hline Flávia & $\begin{array}{l}\text { Graduanda de Letras } \\
-\quad \text { Espanhol e } \\
\text { Português como } \\
\text { línguas estrangeiras } \\
\text { (60 Semestre/UNILA) }\end{array}$ & $\begin{array}{l}\text { Paraguaio- } \\
\text { Brasileira }^{2}\end{array}$ & $\begin{array}{l}\text { Espanhol, } \\
\text { guarani } \\
\text { português }\end{array}$ & $\begin{array}{ll}\text { Participou } & \text { de } \\
\text { todos } & \text { os } \\
\text { encontros } & \\
\text { com } & \\
\text { produção } & \text { de } \\
\text { relatos } & \end{array}$ \\
\hline Luísa & $\begin{array}{l}\text { Mestranda } \\
\text { Literatura } \\
\text { Comparada, egressa } \\
\text { do Curso de Letras, } \\
\text { Artes e Mediação } \\
\text { Cultural, brasileira } \\
\text { (UNILA) }\end{array}$ & Brasileira & $\begin{array}{l}\text { Português e } \\
\text { espanhol }\end{array}$ & $\begin{array}{ll}\text { Participou } & \text { de } \\
\text { todos } & \text { os } \\
\text { encontros } & \\
\text { com } & \\
\text { produção } & \text { de } \\
\text { relatos } & \end{array}$ \\
\hline Paula & $\begin{array}{l}\text { Graduanda de Letras } \\
-\quad \text { Espanhol e } \\
\text { Português como } \\
\text { línguas estrangeiras } \\
\text { (8오요 Semestre/UNILA) }\end{array}$ & Paraguaia & $\begin{array}{l}\text { Espanhol, } \\
\text { guarani e de } \\
\text { português }\end{array}$ & $\begin{array}{l}\text { Participou de } \\
1 \text { encontro }\end{array}$ \\
\hline Elis & $\begin{array}{l}\text { Graduanda de Cinema } \\
\text { e Audiovisual } \quad \text { (2ㅇ } \\
\text { semestre/UNILA) }\end{array}$ & Paraguaia & $\begin{array}{l}\text { espanhol, } \\
\text { guarani } \\
\text { português }\end{array}$ & $\begin{array}{l}\text { Participou de } \\
4 \text { encontros }\end{array}$ \\
\hline
\end{tabular}

Fonte: dados dos pesquisadores (2019).

A partir das informações do Quadro 01, observa-se que a maior parte das extensionistas está em cursos de Letras, com exceção da Elis que cursa Cinema e Audiovisual. Todas frequentam a mesma universidade, sendo que há três estudantes, Luísa, Flávia e Elis, que foram mais atuantes no projeto e uma, Paula, que foi apenas uma vez.

Além disso, verifica-se que uma das extensionistas que produziu o relato é brasileira e falante de espanhol (L2) e outra é brasiguaia, ou seja, nasceu no Paraguai, mas em sua 
Dossiê: Atitudes Linguísticas e Políticas Linguísticas: abordagens interdisciplinares

família fala em português e durante sua escolarização teve aulas de guarani no ensino básico, no entanto, afirma entender pouco e não saber falar o idioma.

Os dados apresentados destacam a característica intercultural do grupo de extensionistas, que "cruza" a fronteira para que os universitários enfrentem desafios importantes na integração dos países latino-americanos. Esse fato contribui para atender os objetivos da universidade, como foi apresentado no início do artigo.

Para refletir sobre como as extensionistas se aproximam de um grupo de crianças linguisticamente diverso, recortam-se, na sequência, trechos dos relatos, nos quais fenômenos linguísticos são observados ${ }^{15}$.

\section{PARTE ANALÍTICA: O TRABALHO/AÇÃO COM A MEDIAÇÃO DE LEITURA}

O questionado bilinguismo paraguaio (MELIÀ, 1997 [1988]; BOYER, 2019), que tem como línguas oficiais o espanhol e o guarani, convive com um falar guarani/jopará utilizado em âmbito familiar e comunitário (estigmatizado) e, outro, o guarani escolar (reconhecido). Essa diversidade está presente nos relatos das universitárias e, aliado a isso, está a presença das diferentes línguas das próprias extensionistas (Quadro 01).

Este contexto é verificado e problematizado logo nos primeiros contatos da equipe com as crianças. De imediato, a mediadora Flávia, que consegue diferenciar os falares dos alunos da escola, relata: "Eles se comunicam muito em guarani entre si, antes da medicação ${ }^{16}$, quando estavam escrevendo os nomes e bem a vontade nos tatames, só conversavam em guarani"17.

Flávia se refere sempre à língua falada pelas crianças, que não é o espanhol, como "guarani". Ela, como explicitado anteriormente, é brasiguaia e por isso consegue identificar as diferentes posturas linguísticas, constatando, com muita rapidez, que elas atuam de formas diversas conforme o contexto e o interlocutor pretendido: quando estão "à vontade"

\footnotetext{
${ }^{15}$ É possível verificar que a questão linguística ocupa parte importante dos registros, mas eles tratam sobre outros temas, por exemplo a mediação literária, a pouca afinidade das crianças com a leitura, a relação entre os alunos etc.

${ }^{16}$ Decidiu-se por manter a grafia embora a palavra indique outro sentido, a intenção da extensionista era se refere à mediação de leitura.

${ }^{17}$ Optou-se por preservar os recortes textuais dos relatos exatamente como estavam, sem qualquer alteração na ortografia, na sintaxe, na concordância ou na língua utilizada.
} 
Dossiê: Atitudes Linguísticas e Políticas Linguísticas: abordagens interdisciplinares

e entre elas utilizam o "guarani", mas quando interagem com as mediadoras optam pelo uso do espanhol.

Já a extensionista brasileira com espanhol como L2, Luísa, em seu primeiro relato, registra: "Quando conversamos sobre a prática percebi que eu preciso manter meu ouvido atento para o espanhol e tenho dificuldade em reconhecer/não entendo quando falam em espanhol de quando estão falando guarani/jopará ${ }^{18}$ e também não entendo, mas além disso também não reconheço o idioma. Flávia pareceu ter o ouvido mais acostumada para diferenciar, conforme disse quando conversamos".

A reflexão da referida universitária revela sua consciência sobre desafios dos encontros linguísticos, ela reconhece o espanhol e sabe que no Paraguai o "guarani/jopará"19 está presente, mas "não tem ouvido" para diferenciá-los, ressente-se por isso e pontua a necessidade de "manter meu ouvido atento". Compreende-se do registro acima que há, por parte da extensionista, uma postura de sensibilidade para a diversidade linguística presente naquele espaço escolar logo no primeiro encontro. Acredita-se que ela pode ter sido já alertada, orientada, seja pela professora coordenadora da ação, seja por seus pares de equipe ou, ainda durante seu curso de graduação ${ }^{20}$.

O recorte seguinte apresenta uma situação bastante discutida pela equipe do projeto, isto é, diante da dificuldade do encontro linguístico, muitos pesquisadores envolvidos no projeto, estudantes e as próprias mediadoras compreendiam ser necessária a participação de falantes de guarani na ação. Eles entendiam que esse gesto poderia ser fundamental para o bom andamento das leituras. Buscou-se, por isso, integrar à equipe uma estudante (Elis) paraguaia falante de guarani/jopará como língua materna na tentativa de verificar a pertinência de um "intérprete".

Paula, formanda em Letras e falante de guarani, também foi convidada a participar da ação como voluntária, mas esteve presente em apenas uma mediação. Sobre o primeiro encontro, já com as mediadoras falantes de guarani, Flávia registra: "Começamos apresentando as meninas que eles não conheciam, e nesse momento a Paula se apresentou em guarani. Na minha percepção, isso mudou a postura de alguns estudantes (poucos), senti

\footnotetext{
${ }^{18}$ Ressalta-se que, na percepção geral das mediadoras, é difícil identificar se as crianças falam em guarani ou jopará, mas dadas as descrições linguísticas do contexto, infere-se que seja o jopará.

${ }^{19}$ A mediadora Flávia sempre se refere à língua das crianças como: "guarani/jopará".

20 É importante destacar que o componente curricular "Mediação Cultural" faz parte da grade de disciplinas do curso de Letras, Artes e Mediação Cultural, do qual participa.
} 
Dossiê: Atitudes Linguísticas e Políticas Linguísticas: abordagens interdisciplinares

que eles se sentiram mais à vontade para se expressar na língua". Já Luísa relata: "As meninas se apresentaram, Paula se apresentou e falou sobre seu nome em guarani, as crianças ficaram empolgadas, em especial os meninos que são mais bagunceiros no grupo, que ficaram bem atentos e fazendo perguntas a ela para que repetisse mais de uma vez seu nome em espanhol e em guarani. Elis também se apresentou dizendo de onde era e as crianças responderam dizendo que sabiam da cidade e que ela ficava distante".

Ambas as mediadoras, Luísa e Flávia, relataram a situação, mas não perceberam muita alteração em relação à aproximação com as crianças. Contudo, para Luísa, a conversa com as mediadoras falantes de guarani, posteriormente à atividade, foi reveladora, pois Elis identificou uma terceira língua nas crianças, o português: "Elis também disse que os meninos agitados estavam fazendo piadinhas misturando o português com o guarani. Seria legal saber mais, para ter noção do domínio deles dos idiomas".

Vale recordar que, na zona de fronteira trinacional, a ponte da amizade liga os dois países (Brasil e Paraguai) e tem trânsito intenso, não apenas de brasileiros consumidores como também de trabalhadores, e o movimento contrário de paraguaios que trabalham em Foz do Iguaçu complementa o fluxo. Nesse trânsito, o espanhol e o português são as línguas hegemônicas e de poder e, particularmente, o português exerce um caráter impositivo por questões de ordem econômica e comercial, já que o comércio de Ciudad del Este é predominantemente movimentado por brasileiros, logo a língua de prestígio é o português nesse contexto, estabelecendo-se de modo valorativo como língua majoritária (ALTENHOFEN, 2013).

Como muitos autores já discutiram, expressa-se um jogo de poder entre as línguas em contato nesta região e a comunidade da escola, na qual a equipe extensionista atua, que é, em sua maioria, formada por trabalhadores informais, próximo a essa zona comercial da cidade. Esse fator intensifica o contato dos trabalhadores com a língua portuguesa, ainda "impondo-se" como um idioma necessário (de negócios), assim como a língua inglesa é vista em outros contextos (CALVET, 2007). Esse ambiente é importante para compreender tanto a proximidade das crianças com a língua do país vizinho como uma forma de curiosidade/necessária expressa em seu comportamento linguístico, além de ser uma postura acolhedora com as extensionistas, uma vez que os estudantes se disponibilizam para a interação pois, ao mesmo tempo em que reconhecem as diferenças, não as tomam 
Dossiê: Atitudes Linguísticas e Políticas Linguísticas: abordagens interdisciplinares

como um obstáculo. Ou seja, é no processo de socialização que o comportamento linguístico dos falantes vai moldando-se de acordo com o contexto de uso e da relação entre eles (MORENO FERNÁNDEZ, 1998). No caso relatado, percebe-se essa postura de abertura para o diálogo tanto da parte das universitárias quanto das crianças em uma gestão democrática das línguas presentes no espaço (SPOLSKY, 2005, 2016).

Retomando o mesmo relato de Luísa, ela finaliza com um enigmático: "Acho que seria interessante começarmos a cumprimentar em guarani". Nota-se, ao longo dos dois primeiros relatos, que essa mediadora está a todo momento buscando formas de aproximação linguística; percebe-se um certo incomodo com a "falta" das línguas. Luísa, como visto no Quadro 01, é brasileira e afirma ter dificuldade com a língua das crianças, talvez por isso o destaque dado ao português e à disponibilidade em aprender o guarani, mesmo que seja apenas a saudação na chegada.

Por outro lado, no conjunto dos relatos de Flávia, é possível perceber que o seu interesse está centrado em estratégias pedagógicas, como formas para organizar a turma, maneiras de "acalmar" as crianças, os horários que a gestão escolar "cede" para o projeto etc. Como já referido, essa mediadora convive há muito mais tempo neste contexto superdiverso, não demonstrando a mesma necessidade de mais conhecimento linguístico relatada por Luísa.

Depois de passadas duas semanas do primeiro relato, Luísa descreve a seguinte situação: "Quando chegou sua vez ele (Carlos ${ }^{21}$ - criança da escola) falou em guarani/jopará, ao que eu respondi que não entendi, (pq não entendi se era guarani mesmo ou español), ele repetiu, notei que era guarani e os outros disseram "en castellano!", pedi que me traduzisse e ensinasse, então fui escrever em guarani na lousa a resposta junto das outras em castellano e assim foi de novo com a outra resposta também em guarani. As crianças então se empolgaram em me ajudar a escrever, tanto em espanhol quanto em guarani".

Identificam-se, no relato acima, que os "medos da falta da língua" começam a ser superados no decorrer dos encontros com as crianças. Nesse sentido, a extensionista vai se sentindo mais à vontade para afirmar que não sabe, não entende em "guarani/jopará"; a turma favorece o diálogo e pede que Carlos fale em espanhol, ou seja, é possível identificar

\footnotetext{
${ }^{21}$ Os nomes dos alunos da escola também são fictícios para preservar suas identidades.
} 
Dossiê: Atitudes Linguísticas e Políticas Linguísticas: abordagens interdisciplinares

que está havendo um intercâmbio, as crianças estão colocando-se à disposição para a conversa com as mediadoras com outros conhecimentos linguísticos.

Tal situação também é narrada por Flávia, "houve uma troca muito especial onde um estudante, Carlos, só fala guarani (ou jopará) e ele não se sente acuado em se expressar em sua língua, não se preocupa de que a gente não vá entender. É bem interessante, sinto que ele se sente muito confortável no espaço. Bom, nesse momento havíamos trocado e quem estava fazendo as perguntas e escrevendo no quadro era a Luísa, foi quando ela perguntou para ele o que ele havia gostado da história e ele disse, em guarani la yacare oñe'e a Luísa pediu para que ele repetisse, os outros colegas foram ajudando, traduzindo, foi muito bonito. Ela escreveu em espanhol, eu escrevi embaixo em guarani. Depois, para a segunda pregunta, aconteceu o mesmo, mas dessa vez os estudantes foram soletrando para a Luísa escrever direto em guarani cuando karai oñorairõ (quando o homem faz guerra) que foi a parte que Carlos não gostou da história".

Nota-se, de forma muito significativa nos trechos destacados, que as mediadoras começaram a recorrer a palavras de outro idioma (espanhol e guarani) em seus registros, esse fenômeno aconteceu aos poucos e não foi orientado, surgiu a medida em que as extensionistas também foram se sentido abertas para as línguas. Em artigo anterior (MARTINY, CORTEZ, 2021 - no prelo, aceito para publicação), discutiu-se, que, ao longo da execução do projeto, quando as mediadoras insistiam em ter contato com o guarani-jopará, a postura das crianças alterou-se. Ambas as mediadoras, Luísa e Flávia, vão relatando as possibilidades do encontro em várias línguas/falares de maneira favorável (GROSJEAN, 2001).

Na relação entre extensionistas e crianças, a situação descrita por Boyer (2019) é reproduzida, no entanto, são desenvolvidas estratégias para efetivar o diálogo. Como exemplo, cita-se o relato de Luísa: "Paulo contou sua história de terror para todos. [....] além dele ter usado palavras em guarani como mitã'i (menino) e ir se corrigindo e repetindo em espanhol. Algo que eu não percebi de imediato, me pareceu muito natural, mas na conversa com as meninas na volta (onde relataram que ele estava fazendo a tradução), pude perceber a sensibilidade que ele teve ao traduzir". A mediadora entende o procedimento de Paulo como "sensível" ao outro, assim como indicam as pedagogias pautadas na interculturalidade crítica (WALSH, 2012). 
Dossiê: Atitudes Linguísticas e Políticas Linguísticas: abordagens interdisciplinares

Percebe-se, nos relatos das extensionistas, que este estar "à vontade" com relação aos encontros linguísticos é progressivo e recíproco, a tal ponto que no último registro da mediadora Flávia há a seguinte observação: “Consegui conversar com a Carolina, me deu todas as respostas em Guarani e depois fazia a tradução. Eu achei curioso e positivo. Acho que conseguimos alcançar nosso objetivo deles se sentirem a vontade com a própria língua, não sentirem vergonha de se comunicar nela, e meio que não importa se nós não entendemos, vamos dar um jeitinho no final". Nota-se que as atitudes são subjetivações, tendo um caráter também de cunho psicológico que igualmente influencia no processo de socialização de uso ou não de determinados falares (MORENO FERNÁNDEZ, 1998).

O comentário final de Flávia minimiza o que antes parecia um grande obstáculo a ser superado. A extensionista assume que em muitos momentos os interlocutores podem até não se entender, mas isso não compromete o desejo de estar juntos, de conviver. Além de pontuar que a ação foi positiva em relação às percepções de práticas interculturais, a mesma mediadora se opõe à postura da extensionista que não participou das discussões iniciais do grupo, pois é ingressante da universidade e talvez por isso não tenha refletido sobres essas questões, então, Flávia pondera: "Tem algo que vem me deixando pensativa que é o fato da Elis chamar a atenção deles em Guarani, $\operatorname{retar}^{22}$ na verdade da mesma forma que os professores fazem em aula. Eu tenho medo disso fazer o caminho contrário do que queremos. Acho que é algo que podemos refletir sobre juntas. Também não acho que ajude, pra mim é algo que não tem a ver com a língua, eles não obedecem não é porque não entendem o que falamos em espanhol, eu acho que tem muito mais a ver com o ambiente não escolarizado, a liberdade que eles sentem na biblioteca os deixam eufóricos demais, a falta de qualquer acesso a bens culturais também... enfim, acho que é algo que devemos refletir juntas sobre".

O trecho destacado revela uma divergência de postura e abertura da estudante para refletir sobre a situação. É notável que Flávia não concorda com a visão de educação de Elis, enquanto essa entende a mediação como uma atividade em que o "erro" é entendido como um problema; aquela, talvez por ter refletido sobre os conceitos da sociolinguística no curso de Letras, compreende o processo de aproximação linguística como algo que deve ser conquistado. Há no comentário de Flávia uma perspectiva mais posicionada como

\footnotetext{
${ }^{22}$ Retar em espanhol significa "chamar a atenção, repreender".
} 
Dossiê: Atitudes Linguísticas e Políticas Linguísticas: abordagens interdisciplinares

mediadora intercultural e isso a faz questionar sobre o espaço e a prática educativa vinculada também à atitude necessária para a integração e o respeito.

Assim sendo, mais uma vez, verifica-se que os ambientes plurilíngues exigem aproximações cuidadosas entre os atores, visibilizando as diferenças sem que estas se tornem obstáculos (MAHER, 2013). Essa postura apenas será possível quando os envolvidos forem conscientes da diferença, atuando de forma horizontal e colaborativa, como pretende ser uma formação sensível para a diversidade linguística e cultural preconizada pela Universidade. Esse é um processo político-linguístico que envolve um jogo de muito diálogo e escuta, de concessões, partilhas, muita confiança, leituras e vivências e tais movimentos devem ocorrer de forma responsável e responsiva entre as crianças, extensionistas, pesquisadores, enfim, cada sujeito envolvido nas práticas de mediação de leitura e no projeto como um todo.

\section{CONSIDERAÇÕES (NÃO) FINAIS}

Diante dos apontamentos expostos, depreendem-se os desafios que o desenvolvimento de um projeto integrado de ensino, pesquisa e extensão possui ao atuar em um espaço sociolinguisticamente complexo, como é o encontrado na Tríplice Fronteira. Esse contexto reflete a necessidade ampla da formação universitária frente às necessidades e às descobertas experimentadas na própria instituição, na qual o plurilinguismo é cotidianamente vivenciado e insistentemente discutido em relação às políticas linguísticas adotadas nas ações que se realizam nas comunidades. Entende-se, assim, que o alunado em formação e egresso é responsável por desempenhar atitudes linguísticas sensíveis aos contextos culturalmente diversos, como acontece no cenário latino-americano. Nesse sentido, constataram-se diferentes posicionamentos das extensionistas no encontro com as crianças paraguaias, entre eles, o comportamento de Flávia que, por ter tido maior contato com as línguas e o contexto educacional paraguaio, não tematiza enfaticamente a questão linguística como uma falta; diferentemente de Luísa que, por ser brasileira, relata ter mais dificuldade e sente necessidade de ter maior conhecimento das línguas presentes no espaço de interação para que aconteça uma maior aproximação. Já Flávia observa mais a situação como se fosse uma terceira pessoa. 
$\mathrm{Na}$ experiência relatada com as mediadoras "intérpretes" (falantes de guarani), as universitárias identificam o uso dessa língua como uma forma de "autorização", ou seja, a possibilidade de se expressar em guarani chama a atenção dos estudantes paraguaios, sendo que o falar passa, a partir dessa postura, a ser valorizado naquele espaço quando utilizado também pelo "outro".

Nos relatos também aparece o uso de uma outra língua, o português, que surge em duas oportunidades: uma quando as crianças brincam entre elas mesclando o guarani e o português e outra quando demonstram curiosidade pela língua. Ambas as práticas remetem ao contexto superdiverso da região trinacional.

Há, ainda, o reconhecimento de uma das mediadoras (Flávia) do projeto dentro da perspectiva da interculturalidade crítica, quando ela analisa que as mediadoras falantes de guarani utilizam o seu saber linguístico compartilhado com o grupo para atuar de forma autoritária, reproduzindo uma postura escolarizada e centrada na ideia de língua "certa", diferente daquela postura pretendida pelo projeto de extensão e pelas discussões levadas a cabo na universidade como um todo. Retoma-se, nesse sentido, a questão em torno da inserção do guarani como língua oficial no país e na educação paraguaia, como uma política oficial, mas que nem sempre gera sua valorização, dando a impressão que se tem duas línguas guaranis: a de casa e a da escola - a primeira, quando reconhecida pelos discentes, é vista como natural, e a segunda, por vezes, considerada distante deles.

Em seus últimos relatos, as mediadoras, concluem que alcançaram seus objetivos no movimento pretendido de aproximação do "outro" para a trocas de saberes. Contudo, por inúmeros fatores contextuais, como greve de professores e fechamento da Ponte da Amizade, não foi possível finalizar o conto bilíngue que seria produzido.

Conclui-se que a mediação da equipe extensionista desempenhou um papel fundamental de gestão das línguas naquele cenário, e que seus comportamentos linguísticos fazem toda a diferença para que não haja (re)afirmação de estigmas, mas se valorizem o saber local e o encontro entre as línguas de forma menos conflituosa, menos desigual.

\section{REFERÊNCIAS DOS CONTOS}

QUIROGA, H. El loro pelado. In: Cuentos de la selva. Santiago, Chile: Pehuén Editores, 2001. p. $10-13$. 
QUIROGA, H. Las medias de los flamencos. In: Cuentos de la selva. Santiago, Chile: Pehuén Editores, 2001. p. 7-9.

QUIROGA, H. La guerra de los yacarés. In: Cuentos de la selva. Santiago, Chile: Pehuén Editores, 2001. p. 13-18.

BUITRAGO, J; YOCKTENG, R. Ilustração de Rafael Yockteng. Eloísa y los bichos. Bogotá, Colombia: Babel Libros SAS, 2009.

HUGHES, E. Salvaje. Buenos Aires, Argentina: Libros del Zorro Rojo, 2014.

BROWNE, A. El túnel. México, Fondo de Cultura Económica, 1993.

\section{REFERÊNCIAS}

ALTENHOFEN, C. Bases para uma política linguística das línguas minoritárias no Brasil. In: NICOLAIDES et al. (Org.). Política e políticas linguísticas. Campinas, SP: Pontes Editores, 2013, p.93-116.

ARNOUX, E. N. de. La Glotopolítica: transformaciones de un campo disciplinario. Rev. Lenguajes: teorías y prácticas, Buenos Aires: Gobierno de la Ciudad de Buenos Aires, Secretaría de Educación, p. 95-109, 2000.

ARNOUX, E. N. de; VALLE, J. Las representaciones ideológicas del lenguaje: discurso glotopolítico y panhispanismo. Spanish in Context. Amsterdam/Filadelfia: John Benjamins Publishing Company, n. VII, v. 1, 2010, p. 1-24.

BLOMMAERT, J. Citizenship, language and superdiversity: towards complexity. Journal of Language, Identity and Education, v. 12, n. 2, p. 193-196, 2013.

BORTONI-RICARDO, S. M. O professor pesquisador: introdução à pesquisa qualitativa. São Paulo: Editora Parábola, 2008.

BOYER, H. Le stéréotypage ambivalent comme indicateur de conflit diglossique. In: BOYER, $\mathrm{H}$. (Ed.). Stéréotypage, stéréotypes: fonctionnements ordinaires et mises en scène. t.4. Paris: L'Harmattan, 2007, p. 39-47.

BOYER, H. Identité (nationale), nationalisme linguistique et politique linguistique. Réflexions à partir de quelques situations contemporaines. Les Cahiers du GEPE, n. 8. Disponível em: Les Cahiers du GEPE: Langue(s) et espace; langue(s) et identité. Strasbourg: Presses universitaires de Strasbourg, $2016.20 \mathrm{em}$ http://cahiersdugepe.misha.fr/index.php?id=2948. Acesso em: 06 jun. 2020. 
BOYER, H. Identidad etnosociolingüística y política lingüística. A propósito del Paraguay contemporáneo. GLOSEMA - Revista Asturiana de Llingüística, v.1, p. 41-51, 2019. Disponível em: https://www.unioviedo.es/reunido/index.php/GLOSEMA/article/view/12957 . Acesso em: 06 jun. 2020.

BRASIL. IMEA - INSTITUTO MERCOSUL DE ESTUDOS AVANÇADOS, COMISSÃO DE IMPLANTAÇÃO DA UNIVERSIDADE FEDERAL DA INTEGRAÇÃO LATINO-AMERICANA. A UNILA em Construção: um projeto universitário para a América Latina. Foz do Iguaçu: Publicações IMEA, 2009.

BRASIL. UNILA - UNIVERSIDADE FEDERAL DA INTEGRAÇÃO LATINO-AMERICANA. Estatuto. Foz do Iguaçu, PR: UNILA, 2012. Disponível em: < https://portal.unila.edu.br/institucional/documentos-oficiais/estatuto-da-unila. Acesso em: 05 jun. 2020.

BRASIL. UNILA - UNIVERSIDADE FEDERAL DA INTEGRAÇÃO LATINO-AMERICANA. Plano de Desenvolvimento Institucional 2012-2017. Foz do Iguau, PR: UNILA, 2013. Disponível em: https://portal.unila.edu.br/institucional/documentos-oficiais/pdi-2013-2017. Acesso em: 05 jun. 2020.

BRASIL. UNILA - UNIVERSIDADE FEDERAL DA INTEGRAÇÃO LATINO-AMERICANA. Plano de Desenvolvimento Institucional 2019-2023. Foz do Iguaçu, PR: UNILA, 2019. Disponível em: https://www.unila.edu.br/sites/default/files/files/PDI verso CONSUN-1.pdf. Acesso em: 05 jun. 2020.

CALVET, L. J. Sociolinguística: uma introdução crítica. Trad. Marcos Marcionilo. São Paulo: Parábola, 2002.

CALVET, L. J. As políticas linguísticas. São Paulo: Parábola, 2007.

CANDAU, V. M. F. Diferenças culturais, interculturalidade e educação em direitos humanos. Educ. Soc. [online]. vol.33, n.118, 2012, p. 235-250. Dipsonível em: https://www.scielo.br/scielo.php?pid=S010173302012000100015\&script=sci_abstract\&tlng =pt. Acesso em 09 de jun. 2020.

CARVAlHAL, T. P. Avaliação de Política e Planejamento da Linguagem: um estudo sobre os efeitos de um projeto de integração regional. 2016. $150 \mathrm{f}$. Tese (Doutorado em Estudos de Linguagem), Programa de Pós-Graduação em Estudos de Linguagem, da Universidade Federal Fluminense (UFF), Niterói, RJ, 2016.

CARVALHO, S. da C. As relações de status entre as línguas na implementação em processo de uma proposta acadêmica bilíngue em um cenário institucional multilíngue latino-americano. 2012. 165 f. Dissertação (Mestrado em Linguística Aplicada) - Programa de Pós-Graduação em Letras, Universidade Federal do Rio Grande do Sul (UFRGS), Porto Alegre, RS 2012.

MUÑOZ, A. M. E. L'intercompréhension dans le contexte plurilingue de l'Université Fédérale de l'intégration Latino-Américaine (UNILA): expériences, contact et interaction plurilingue. 
2016, 271 f. Thèse (Doctorat en Sciences du langage) - LIDILEM - Linguistique et Didactique des Langues Étrangères et Maternelles, Université de Grenoble 3, Grenoble, France, 2016.

FERREIRA, L. M. L.. Práticas de leitura e escrita ao longo dos cursos de graduação na UNILA: subsídios para o ensino de línguas adicionais. Revista Intercâmbio. São Paulo: LAEL/PUCSP, p. 29-50, 2015.

GROSJEAN, F. Life with two languages: an introduction to bilingualism. 11. ed. Cambridge, Massachusetts/London: Harvard University Press, 2001.

GEERTZ, C. A interpretação das culturas. I.ed., IS. reimpr. Rio de Janeiro: LTC, [1926] 2008.

MARIANI, B. Colonização linguística. Línguas, política e religião no Brasil (séculos XVI a XVIII) e nos Estados Unidos da América (século XVIIII). Campinas: Pontes, 2004.

GUIMARÃES, E. Enunciação e política de línguas no Brasil. Revista Letras: Espaços de Circulação da Linguagem, n. 27, jul./dez., p. 47-53, 2006.

MARTINY, F. M.; CORTEZ, M. Práticas e percepções linguísticas de alunos em uma escola paraguaia de fronteira. Fórum Linguístico, n. 2, 2021. No prelo.

MELIÀ, B. Pueblos Indígenas en el Paraguay: Demografía histórica y análisis de los resultados del Censo Nacional de Población y Viviendas, 1992. DGEEC, Fernando de la Mora, Paraguay, 1997.

MORENO FERNÁNDEZ, F. Principios de sociolingüística y sociología del lenguaje. Barcelona: Ariel, 1998.

NIRO, M. Sobre consensos y disensos en la Ley de lenguas de Paraguay. In: BOYER, H.; PENNER, H. (Dir.). Le Paraguay bilingue / El Paraguay bilingue. Paris: L'Harmattan, 2012, p. 135-219.

PENNER, H. Jopara: la face meprisée du guarani ou/et du bilinguisme? In: Henri Boyer (Dir.), Hybrides linguistiques. Geneses, statuts, fonctionnements, Paris: L'Harmattan, 2010, p.175201.

PENNER, H. La Ley de lenguas en el Paraguay: un nuevo impetu coercitivo? In: Carmen Alen Garabato, Ksenija Djordjevic Leonard, Patricia Gardies, Alexia Kis-Marck, Guy Lochard (Ed.), Rencontres en sciences du langage et de la communication, Paris: L'Harmattan, 2016a, p. 279-307.

PENNER, $\mathrm{H}$. La ley de lenguas en el Paraguay: ¿un paso decisivo en la oficialización de facto del guaraní? Rev. Signo y Seña, n.30, p.108-136, 2016b. Disponível em: https://dialnet.unirioja.es/servlet/articulo?codigo=6482723. Acesso em: 09 jun. 2020.

RAJAGOPALAN, K. A norma linguística do ponto de vista da política linguística. In: LAGARES, X. C.; BAGNO, M. (Org.). Políticas da norma e conflitos linguísticos. São Paulo: Parábola Editorial, 2011, p. 121-128. 
RAJAGOPALAN, K. Política linguística: do que é que se trata, afinal? In: NICOLAIDES, C. et al. (Orgs.). Política e políticas lingüísticas. Campinas, SP: Pontes Editores, 2013, p, 19-42.

RIBEIRO, J.; NUNES, N. Discursos sobre o bilinguismo em contexto intercultural de Ensino na unila: dois pesos e outras medidas. Revista Cenas Educacionais, Caetité - Bahia - Brasil, v. 3, n. e7481, p. 1-26, 2020.

RODRIGUEZ-ALCALÁ, C. Terminologia sociolingüística e nacionalismo: análise das análises do estatuto atual da língua guarani no Paraguai. In: ORLANDI, E. P. (Org.) História das idéias lingüísticas: construção do saber metalinguistico e constituição da língua nacional. Cáceres: Pontes; Unemat, 2001, p.257-271.

RODRIGUEZ-ALCALÁ, C. La langue comme problème urbain: le guarani à la campagne et dans l'espace public de la ville. Langage et société, v.3, n.101, p. 55-97, 2002. Disponível em :< https://www.cairn.info/revue-langage-et-societe-2002-3-page-55.htm. Acesso em: 16 jun. 2020.

SOUSA, S. C. T. de.; ROCA, M. del P. Introdução para uma compreensão ampliada de Política Linguística. In: SOUSA, S. C. T. de.; ROCA, M. del P. (Orgs.). Políticas linguísticas: declaradas, praticadas e percebidas. João Pessoa: Editora da UFPB, 2015, p. 07-23.

SPOLSKY, B. Language Policy. In: COHEN, J. et al. Procedings of the 4th International Symposium on Bilingualism. Somerville, MA: Cascadilla Press, 2005, p. 2152-2164. Disponível em: http://www.lingref.com/isb/4/168ISB4.PDF. Acesso em: 28 jul. 2018.

SPOLSKY, B. Para uma Teoria de Políticas Linguísticas. ReVEL. Tradução de Paloma Petry. Revisão técnica de Pedro M. Garcez. v. 14, n. 26, 2016, p. 32-44. Disponível em: http://revel.inf.br/files/f69d74cdefbd9c6efb801010f2ac8b13.pdf. Acesso em: 30 ago. 2019.

STURZA, E. R. Espaço de enunciação fronteiriço e processos identitários . Pro-Posições, Campinas, v. 21 , n. 3 (63), p. 83-96, set./dez. 2010. Disponível em: < https://www.scielo.br/pdf/pp/v21n3/v21n3a06.pdf. Acesso em: 20 ago. 2020.

WALSH, C. Interculturalidad y (de)colonialidad: perspectivas críticas y políticas. Visão Global. Joaçaba, v. 15, n. 1-2, jan./dez., 2012, p. 61-74 Disponível em: https://portalperiodicos.unoesc.edu.br/visaoglobal/article/view/3412. Acesso em 09 jun. 2020.

ZUCCOLILLO, C. M. R. Língua, nação e nacionalismo: um estudo sobre o guarani no Paraguai. 2000. 254 f. Tese (Doutorado em Linguística) - Instituto de Estudos da Linguagem, Universidade Estadual de Campinas, Unicamp, Campinas-SP, 2000. Disponível em: http://bdtd.ibict.br/vufind/Record/CAMP_a54be64db66088215116aa73a1954192. Acesso em: 09 jun. 2020. 
Recebido em 08 de julho de 2020.

Aprovado em 16 de outubro de 2020.

(c) (1)() 